\title{
NECROLÓGICA. MARÍA JESÚS RUBIERA MATA (1942-2009)
}

\author{
Luis F. Bernabé Pons y José F. Cutillas Ferrer
}

Apenas seis meses después de la desaparición de su marido y compañero en la Universidad, Míkel de Epalza, murió el 7 de junio de 2009 en Alicante María Jesús Rubiera Mata, debido al agravamiento de una dolencia crónica que empeoró sensiblemente durante la convalecencia de su esposo. Así, en muy poco tiempo, el Área de Estudios Árabes e Islámicos se ha visto dolorosamente desprovista de dos bastiones fundamentales que la convirtieron en lo que es hoy. El mundo científico y académico se ha visto asimismo sorprendido por la desaparición de una profesora y científica de primer orden, sin la cual es difícil comprender el avance de algunas áreas de los estudios árabes en España. En plena producción intelectual -encabezaba en el momento de su muerte un Proyecto de Investigación del Ministerio sobre "La literatura de la Alhambra"1-, su desaparición corta de forma abrupta unas investigaciones que, desde la madurez científica, estaba acometiendo en los últimos tiempos.

Nacida en 1942 en Madrid y madrileña de militancia toda su vida, su padre fue el hombre de negocios y productor de cine Jesús Rubiera, que inoculó en ella el gusto por las buenas películas que le acompañó siempre. Se licenció en 1965 con Premio Extraordinario en Filología Semítica en la Universidad Complutense de Madrid, donde obtuvo el doctorado en 1972 con una tesis sobre el poeta y visir granadino Ibn al-Ŷayyāb (Granada, 1982), tesis dirigida por su maestro, Elías Terés, y cuya aportación más sobresaliente fue el descubrimiento entre la epigrafía de los muros de la Alhambra de poemas de al$\hat{Y}$ ayyāb. Sus inicios como investigadora y docente fueron en la Universidad Complutense como Profesora Ayudante (1966) y Profesora Adjunta (1975), iniciando unos temas de investigación en los que se vería la influencia del que ella siempre calificó como el mejor de sus maestros, el citado Elías Terés. Una fotografía que ella tenía en mucha estima muestra a un grupo de estudiantes complutenses (María Jesús Rubiera ente ellos) rodeando a Elías Terés en una salida de campo a Montánchez.

1. Proyecto de Investigación del Ministerio de Ciencia e Innovación HUM2007-65006-C0201/FILO "La literatura de la Alhambra". 
Sin embargo, el período más fructífero de su carrera docente e investigadora lo realizó en Alicante adonde se trasladó en 1982. En 1985 ganó la cátedra de Estudios Árabes e Islámicos en la Universidad de Alicante y desde entonces fue desarrollando -científica y académicamente- el Área de Estudios Árabes e Islámicos junto con Míkel de Epalza Ferrer. Gracias a su esfuerzo investigador, plasmado en numerosas publicaciones de ámbito nacional e internacional, logró un importante prestigio para los Estudios Árabes e Islámicos en la Universidad de Alicante.

Su labor docente e investigadora está jalonada de premios de investigación y de obras que han supuesto un aporte importante para el avance de los Estudios Árabes e Islámicos, tanto por sus traducciones y estudios de Literatura árabe y andalusí, de la Historia de al-Andalus, la Lengua árabe y los arabismos, la Toponimia y Literatura comparada árabe-románica, lo que ha enriquecido la percepción de la civilización árabe-islámica en su área de influencia. El homenaje que le fue tributado en las páginas de esta misma revista, en el que se revisaba de forma minuciosa su obra, nos exonera aquí de hacer más que un rápido bosquejo de los caminos investigadores de María Jesús Rubiera.

De sus primeras investigaciones enraizadas en su tesis doctoral sacó María Jesús Rubiera las ramas principales de lo que iban a ser tres de sus principales vías de investigación (también tres de sus pasiones): el reino nazarí de Granada, la literatura de al-Andalus y la Alhambra de Granada. Granada fue para ella una especie de lugar de iniciación. Iniciación a la poesía de los grandes kuttâb granadinos, que ella traducía con pasmosa habilidad; iniciación al mundo nazarí, entre cuyos enrevesadísimosos laberintos se movía con soltura; e iniciación asimismo al mundo estético árabe, hecho espacio en los versos epigrafiados en la Alhambra y Generalife, en sus jardines palatinos y en su imponente majestuosidad de palacio real. Granada y la Alhambra fue para ella una pasión que recorrió su vida y que puede ser rastreada a lo largo de su curriculum, desde las grandes familias nazaríes, pasando por la poesía y la Alhambra, hasta llegar a los moriscos granadinos y la familia de los MuleyFez, a la que ella, capaz de verla en perspectiva diacrónica, encajó en su justo valor. Su último trabajo, publicado en Al-Qanțara y que le llegó cuando su estado ya era muy delicado, le había llenado de ilusión investigadora pero especialmente de una suerte de sentimiento de recompensa al haber dado luz a lo que ella juzgaba uno de los arcanos de la dinastía nazarí.

De la poesía granadina marchó María Jesús Rubiera al conjunto de la literatura de al-Andalus de la mano cercana de Elías Terés y algo más lejana de García Gómez. Aunque nunca abandonó, en ciencia y en divulgación, a su amada poesía epigráfica alhambreña, un encargo de Elías Terés para un libro de conjunto sobre las literaturas de la Península Ibérica, le hizo ver la necesidad de visiones amplias acerca de lo que se llamaba entonces literatura hispanoárabe. Sus trabajos y libros de conjunto sobre literatura andalusí, uno de ellos traducido al árabe en Egipto, siguen siendo manuales de refererencia sobre la 
materia, con sus traducciones hechas ad hoc y su esfuerzo continuo en la explicación estética y estilística de los productos literarios de al-Andalus. Ya radicada en Alicante, volcó parte de su esfuerzo en poner negro sobre blanco a los poetas del Sarq al-Andalus, muy desconocidos en un Mediterráneo que, pese a presumir de su pasado árabe, apenas tenía noticia de las poesías de Ibn Jafaya o Ibn al-Labbana. Las versiones que de sus traducciones se hicieron al catalán y al valenciano llegó a hacer popular en la Comunidad Valenciana, pero también en Cataluña o en Baleares, la poesía sharqí.

La literatura clásica le llevó asimismo por derroteros más específicos, como las narraciones y su valor simbólico (la mesa de Salomón, la conquista de al-Andalus...) y la estética y la apreciación de la belleza en la civilización árabe. Uno de sus más reputados libros, La arquitectura en la literatura árabe. Datos para una estética del placer, traducido al italiano y al alemán, fue el trampolín para sus investigaciones y reflexiones sobre las categorías estéticas (pero también sociales, políticas y simbólicas) árabes, categorías que luego aplicó a sus trabajos en torno al amor o a la mujer entre los árabes, a la que se había acercado agrupando en un libro a las poetisas surgidas en al-Andalus. Igualmente, la literatura le condujo a territorios más fronterizos: tal sus estudios sobre la presencia árabe en autores medievales y contemporáneos, sobre el origen árabe de algunos cuentos, o sobre la presencia románica extra-andalusí en las jarchas engastadas en algunas de las moaxajas conservadas.

La huella luminosa de su maestro Elías Terés también se dejaba sentir en el interés de María Jesús Rubiera por la historia y la sociedad de al-Andalus. Interés global, de voluntad hermenéutica de toda una sociedad, su investigación le llevó de las instituciones sociales a la ordenación del territorio, de la toponimia a la arqueología, de la política de las cortes árabes taifales a las conversiones medievales. Su pretensión era explicar un territorio, un personaje o un fenómeno acudiendo a la mayor cantidad de análisis posible: lingüístico, geopolítico, social... Sus aportaciones a la estructuración vial del Sharq Al-Andalus, conjugando territorio, política y toponimia, quedan como ejemplos de trabajos en los que la realidad andalusí cobra una entidad propia. Es una pena que no se decidiera nunca a publicar algunos trabajos en este ámbito que hubieran contribuido al debate.

Sus trabajos acerca de los moriscos, por acabar con el ámbito cercano a la revista que acoge estas páginas, venían igualmente de su curiosidad e interés por las manifestaciones culturales andalusíes. Ya se ha mencionado su artículo sobre la familia de los Muley, pero igualmente son importantes sus trabajos sobre el Mancebo de Arévalo, sobre el que dirigió un Proyecto de Investigación en la Universidad de Alicante, sacando a la luz el fabuloso escondite de Algecira del Conde, donde un día de principios del siglo XVI se ocultara el sabio 'Ali Sarmiento, espía del Rey Católico, o proponiendo la identidad judeoconversa -más tarde morisca- del mismo autor castellano, trasmutando un desconocido autor en un perfecto representante de los tres grupos que aún se hacían notar en la España moderna. 
Todo este esfuerzo reflexivo e investigador fue parejo al esfuerzo académico y administrativo por implantar y desarrollar los Estudios Árabes e Islámicos en la Universidad de Alicante, primero con la implantación de la Licenciatura y más tarde con el Doctorado en Filología Árabe. Toda esta labor ha tenido su reflejo en los diferentes investigadores a los que supo formar y atraer para ir fomentando áreas de investigación, algunas novedosas en el ámbito universitario español. Buena conocedora de los entresijos de la gestión universitaria, María Jesús Rubiera siempre estuvo atenta a empujar a su Área -también a su Departamento- a avanzar en todos los órdenes.

Del mismo modo, intentó dotar a su Área de Estudios Árabes e Islámicos de los instrumentos académicos usuales de difusión de la investigación. De esa voluntad, y del conocimiento que ella tenía del mundo académico, surgió la revista Sharq Al-Andalus. Estudios Árabes e Islámicos, dirigida por ella en varios números y que acogió en su número 10-11 un homenaje tributado por el mundo académico en el que se explora de forma minuciosa su vida y su obra científica. Tras el congreso "La voz de mudéjares y moriscos", organizado por ella en Alicante, y la publicación de sus actas en el número 12 de la revista, se decidió que ésta se especializara en el mundo mudéjar y morisco, pasando a denominarse Sharq Al-Andalus. Estudios Mudéjares y Moriscos. Su afán por incrementar los ámbitos de cooperación interdisciplinar le hizo interesarse por campos de la expresión cultural -como el cine o el teatro- que no son los usuales dentro de nuestros ámbitos de estudio, buscando elementos interdiscursivos que revelaran características de la cultura árabe. De la misma forma, nunca quiso dejar pasar los avances que las nuevas tecnologías ofrecían al mundo docente y académico. Fue ella de las primeras que aprendió a usar los programas informáticos de tratamiento de textos en árabe y, entre otras iniciativas, emprendió la creación y dirección del Portal "Literatura de Mudéjares y Moriscos", dentro de la Biblioteca Virtual "Miguel de Cervantes" de la Universidad de Alicante. Trabajadora empedernida, su fuerte carácter le impedía oír hablar de una jubilación anticipada, que le aconsejaba su delicada salud, y su enfermedad final la sorprendió con varios trabajos en prensa y con muchas anotaciones recogidas para trabajos futuros. Aún en sus últimas semanas repasaba con compañeros de Alicante y de Granada los avatares de su Proyecto de Investigación acerca de la literatura sobre la Alhambra, opinaba sobre las necesidades docentes del Área o pensaba en nuevos libros para leer. Su trabajo y sus ideas perviven en las labores de muchos de sus discípulos que siguen en varios campos con las actividades que ella inició en Alicante.

\section{Bibliografía de María Jesús Rubiera Mata}

«El significado del nombre de los Banu Ašqilūla», Al-Andalus, 31, 1966, pp. 377-388.

«Tres topónimos de la frontera granadina», Al-Andalus, 32, 1967, pp. 217-220. 
«El Dūu-l-Wizaratayn Ibn al-Hakim de Ronda», Al-Andalus, 34, 1969, pp. 105-125.

"Datos sobre una 'madrasa' en Málaga anterior a la nașrí de Granada», $\mathrm{Al}$ Andalus, 35, 1970, pp. 223-226.

«Los poemas epigráficos de Ibn al-Ŷayyāb en la Alhambra», Al-Andalus, 35, 1970, pp. 453-473.

«De nuevo sobre las tres morillas», Al-Andalus, 37, 1970, pp. 133-143.

, «Sur un possible auteur de la chronique intitulée al-hulal al-mawsiyya fi dikr al-ajbar al-marrakusiyya», II Coloquio Hispano-Tunecino, Madrid, Instituto Hispano-Árabe de Cultura, 1973, pp. 143-146.

"La poesía cinegética árabe», en Orientalia hispanica sive studia F.M. Pareja dedicavit, Leiden, E.J. Brill, 1974, pp. 566-579.

, «El arráez Abū Sa'īd Farāŷ ibn Ismā'îl, gobernador de Málaga y epónimo de la segunda dinastía nasrí de Granada», Boletín de la Asociación Española de Orientalistas, 11, 1975, pp. 127-133.

«De nuevo sobre los poemas epigráficos de la Alhambra», Al-Andalus, 41, 1976, pp. 207-211.

, «Ibn Zamrak, su biográfo Ibn al-Ahmar y los poemas epigráficos de la Alhambra», Al-Andalus, 42, 1977, pp. 447-451.

" «n aspecto de las relaciones entre Ifriqiya hafsí y la Granada nasrí, la presencia tunecina en las tariqat místicas granadinas», Les Cahiers de Tunisie, 26, 103-104, 1978, pp. 165-172.

"El vínculo cognático en al-Andalus», Actas del I Congreso de Historia de Andalucía, Córdoba, Caja de Ahorros de Córdoba, 1978, pp. 121-124.

«Las décimas del Profeta, versos con epanadiplosis en la poesía hispanoárabe», Al-Qanțara, 1, 1980, pp. 55-64.

«La mesa de Salomón», Awrāq, 3, 1980, pp. 55-64.

, «iteratura hispano-árabe», Historia de las literaturas hispánicas no castellanas, Madrid, Taurus, 1980, pp. 141-176.

«Poesía epigráfica en la Alhambra y el Generalife», Poesía, 12, 1981, pp. 17-76.

, «Los Banu Escallola, una dinastía granadina que no fue», Andalucía Islámica, 2, 1981, pp. 85-94.

«La literatura arábigo-andaluza», Historia de Andalucía, 1981, pp. 42-79.

- La arquitectura en la literatura árabe. Datos para una estética del placer, Editora Nacional, 1982; reed. Madrid, Hiperión, 1988 (trad. italiana L'immaginario e l' architettura nella letteratura araba medievale, Milano, Marietti, 1990; trad. alemana Rosen der Wurste. Die Architektur in der Arabischen Literatur, Munich, Rose Noire, 2001).

Ibn al-Ŷayyāb, el otro poeta de la Alhambra, Madrid-Granada, Instituto Hispano-Árabe de Cultura, 1982; reed. Granada, Patronato de la Alhambra, 1994. 
Al-Mu tamid Ibn ${ }^{c} A b b \bar{a} d$. Poesías. Antología bilingüe, Instituto HispanoÁrabe de Cultura, Madrid (Madrid, 1982; 1987²).

«Literatos del Sharq al-Andalus, Abu Salt de Denia e Ibn Dihya de Calpe», Revista del Instituto de Estudios Alicantinos, 36, 1982, pp. 33-43.

, «La descripción poética de los palacios árabes: datos para una definición de género», en Actas del IV coloquio hispano-tunecino. Palma de Mallorca, 1979, Instituto Hispano-Árabe de Cultura, 1982, pp. 213-215.

«Algunos problemas cronológicos en la biografía de al-Mu'tamid de Sevilla: la conquista de Silves y el matrimonio con Rumaykiyya», en Actas de las jornadas de cultura árabe e islámica (1978), Madrid, Instituto Hispano-Árabe de Cultura, 1982, pp. 231-245.

, «El poeta Ibn Al-Labbāna en Mallorca», Butlletí de la Societat Arqueològica Lul.liana, 39, 1983, pp. 503-509.

«Elías Terés (1915-1983)», Awraq, 5-6, 1983, pp. 302-303.

" «Antigua literatura árabe», en Historia universal de la literatura, Barcelona, Orbis, 1983, pp. 1-17.

, «Rafals y raales; ravals y arrabales, reals y reales», Sharq Al-Andalus, 1, 1984, pp. 117-122.

«Posible identificación de Ibn al-Royolo de Denia, ministro de al-Muqtadir de Zaragoza (s. XI)», Sharq Al-Andalus, 1, 1984, pp. 151-152.

«Algunas precisiones sobre los dialectos arábigo-granadino y arábigo-valenciano», Sharq Al-Andalus, 1, 1984, pp. 317-320.

"Álava y los alaveses en los textos árabes medievales», en Congreso de estudios históricos "La formación de Álava". 650 Aniversario del pacto de Arriaga (1332-1982), Álava, Diputación de Álava, 1984, pp. 385-393.

" «oponimia arábigo-valenciana. Falsos antropónimos beréberes», Cuadernos de Filología de la Universidad de Valencia, 1, 1984, pp. 317-320.

«La corte literaria de Sa'id de Menorca», Revista de Menorca, 75, 1984, pp. 105-138.

«Valencia en el Pacto de Tudmir», Sharq Al-Andalus, 2, 1985, pp. 119-120.

, «Una república musulmana en Xàtiva (s. XI)», Xàtiva, 25, 1985, pp. 101-104. «Los omeyas. Arte y literatura», Cuadernos Historia 16, 25, 1985, pp. 19-24. Els noms àrabs de Benidorm i la seua comarca / Los nombres árabes de Benidorm y su comarca, Alicante, Universidad de Alicante, 1985.

Villena en las calzadas romana y árabe, Alicante, Universidad de Alicante, 1985.

La taifa de Denia, Instituto de Cultura Juan Gil Albert. Excma. Diputación de Alicante, Alicante, 1985, $1988^{2}$.

"Muhammad ben isa ibn al-Labbana», en Antología de escritores benisseros, Ajuntament de Benissa (Alicante), 1985, pp. 11-18. 
«Rasgos mediterráneos de la poesía de al-Andalus», en II Encontre d'escriptors del Mediterrani. "Literatura i societat", Valencia, Ayuntamiento de Valencia, 1985, pp. 198-201.

«Madjrìț, Encyclopédie de l'islam, Leiden, E.J. Brill, 1985, vol. V, pp. 95-96.

«Estructura de cantar de gesta en uno de los relatos de la conquista de Al-Andalus», Revista del Instituto Egipcio de Estudios Islámicos (Madrid), 23, 1986, pp. 64-78.

«El vocablo árabe 'sikka' en su acepción de vía y sus posibles arabismos en la toponimia hispánica, Aceca, Seca y Villaseca», Sharq Al-Andalus, 3, 1986, pp. 129-131.

«Los cristianos toledanos bajo dominación musulmana», en Simposio Toledo hispano-árabe, Toledo, Colegio Universitario de Toledo, 1986, pp. 129-133. (Con M. de Epalza.)

, «Estat actual dels estudis de toponimia valenciana d'origen àrab», en $X$ Col-loqui General de la Societat d'Onomàstica, Valencia, Universidad de Valencia, 1986, pp. 420-426. (Con M. de Epalza.)

, «La sofra (sujra) en el Sharq al-Andalus antes de la conquista catalanoaragonesa», Sharq Al-Andalus, 3, 1986, pp. 33-37. (Con M. de Epalza.)

"Los estudios de toponimia hispano-árabe a la luz de dos publicaciones recientes», Sharq Al-Andalus, 4, 1987, pp. 365-366.

«El príncipe hastiado, Muhammad ibn Abdalmalik ibn 'Amir, efímero soberano de Orihuela y Murcia», Sharq Al-Andalus, 4, 1987, pp. 73-81.

, «La lengua romance de las jarchas (a una jarcha en lengua occitana)», $A l$ Qanțara, 8, 1987, pp. 319-329.

Bibliografía de la literatura árabe, Alicante, Universidad de Alicante, 1987.

Xàtiva musulmana (segles VIII-XIII), Xàtiva, Ajuntament de Xàtiva, 1987. (Con Míkel de Epalza.)

"Las inscripciones árabes de Játiva: una hipótesis y una propuesta de denominación de estilo», en Homenaje al Prof. Darío Cabanelas Rodríguez, con motivo de su LXX Aniversario, Universidad de Granada, 1987, vol. II, pp. 293-295.

"Los precedentes geopolíticos musulmanes del señorío de Villena», en Congreso de historia del señorío de Villena, Albacete, Instituto de Estudios Albacetenses “D. Juan Manuel”, 1987, pp. 357-360.

«La lengua árabe y la lengua valencianas», en Las lenguas prevalencianas, Alicante, Universidad de Alicante, 1987, pp. 93-95.

«Nueva aproximación al estudio literario de las jarchas», Sharq Al-Andalus, 5, 1988, pp. 89-100.

«El Baix Vinalopó durant l'època àrab», La Rella, 6, 1988, pp. 49-56. 
«La conquesta de València per Jaume I com a tema literari en un testimoni de l'esdeveniment: Ibn al-Abbar de València», L'Aiguadolç, 7, 1988, pp. 33-34.

«La función estética del agua en la civilización arábigo-islámica», en Agua y poblamiento musulmán. Aigua i poblament musulmà, Benissa, Ajuntament de Benissa, 1988, pp. 11-12.

«El Du-l-Wizaratayn ibn al-Hakim de Ronda», en Estudios sobre Ronda y su serranía. V centenario de la incorporación de Ronda a la corona castellana (14851985), Granada, Universidad de Granada, 1988, pp. 205-218.

Introducció a la literatura hispano-àrab, Alicante, Universidad de Alicante, 1989.

, «Els topònims aràbigo-catalans del Baix Segura (Alacant)», Sharq Al-Andalus, 6, 1989, pp. 159-160.

"Cançonetes de tipus kharja en la literatura catalana», Miscel-lania Joan Fuster. Estudis de llengua i literatura, Barcelona, Abadía de Montserrat, 1989, pp. 1-8.

«Lo árabe en la poesía de Sergio Macías», Prólogo a Sergio Macías, Tetuán en los sueños de un andino, Betania, 1989, pp. 13-15.

«Relacions d'anada i tornada entre la poesía provençal i la literatura àrab a través dels catalans: kharges en llengua occitana», en Actes del vuité col-loqui internacional de llengua i literatura catalanes, Barcelona, Abadía de Montserrat, 1989, vol. II, pp. 237-244.

«Un insólito caso de conversas musulmanas al cristianismo. Las princesas toledanas del siglo XI», en A. MuÑIZ FERNÁNDEZ (ed.), Las mujeres en el cristianismo medieval. Imágenes teóricas y cauces de actuación religiosa, Madrid, Asociación Cultural Al-Mudayna, 1989, pp. 341-347.

«Oficios nobles, oficios viles», en La mujer en al-Andalus. Reflejos históricos de su actividad y categorías sociales, Universidad Autónoma de Madrid, 1989, pp. 71-76.

«Una fórmula elocutiva en la lírica tradicional románica i una altra possible khartja occitana», A Sol Post. Estudis de Llengua i Literatura, 1, 1990, pp. 193-196.

«La cultura musulmana: Pensament, Llenguatge i formes literàries (Aspectes de la poesía arábigo-valenciana: el paradís i el paradís perdut)», En torno al 750 Aniversario. Precedentes y consecuencias de la conquista de Valencia, Valencia, Consell Valencià de Cultura, 1989, pp. 98-106.

«Tirant lo Blanc i els moros», L'Aiguadolç, 11-12, 1990, pp. 33-40.

«El Tirant i la literatura àrab», Serra d'Or, 371, 1990, pp. 57-58.

" «Tunis dans une nouvelle du dramaturgue espagnol Félix Lope de Vega», Revue d'Histoire Maghrébine, 63, 1990, pp. 417-421.

«El món cavalleresc àrab i el mòn cavalleresc del Tirant», Afers, 1990, pp. 267-274. 
Poesía femenina hispanoárabe, Madrid, Castalia, 1990.

«La toponimia árabe de Madrid», en Madrid del siglo IX al XI, Madrid, Consejería de Cultura de la Comunidad de Madrid, 1990, pp. 165-170.

«Una nueva hipótesis sobre la lengua de las jarchas a partir de las investigaciones de Rafael Lapesa», en J. MuÑOz GARRIGós (coord.), Homenaje al Profesor Lapesa, Murcia, Universidad de Murcia, 1990, pp. 227-232.

«Dos cuentos árabes medievales en la literatura hispánica, 'El Viejo Celoso' y 'El Aterrizaje sin Cola'», Sharq Al-Andalus, 8, 1991, pp. 417-421.

«Introducción a la nueva edición», Jaime Oliver Asin: historia del nombre "Madrid", Madrid, Instituto de Cooperación con el Mundo Árabe, 1991, pp. 1-16.

«Les premiers mores convertis ou les prémises de la tolérance», en Louis Cardaillac (ed.), Tolède, XII-XIII. Musulmans, chrétiens et juifs. Le savoir et la tolérance, Madrid, Alianza Editorial, 1991, pp. 102-111.

«Presencia románica extra-andalusí en las jarchas», Actas del primer congreso internacional sobre poesía estrófica árabe y hebrea y sus paralelos romances, Madrid, Instituto de Cooperación con el Mundo Árabe, 1991, pp. 289-295.

, «Presentación», en Manuel EspinAR Moreno, Vivo la Alhambra. El agua, Granada, Proyecto Sur de Ediciones, 1991, pp. 3-4.

«Arquetipos ideales de la ciudad árabe», en Simposio internacional sobre la ciudad islámica. Ponencias y comunicaciones, Zaragoza, Institución Fernando el Católico, 1991, pp. 57-64.

"Ibn al-Abbâr i el seu temps», en Ibn al-Abbâr. Polític i escriptor àrab valencià (1199-1260), València, Generalitat Valenciana, Conselleria de Cultura, Educació y Ciència, 1991, pp. 13-18.

"Joan Fuster y la poesía árabe», Sharq Al-Andalus, 9, 1992, pp. 89-92.

, Literatura hispano-árabe, Madrid, Mapfre, 1992 (trad. árabe Al-Adab al-andalusî, El Cairo, al-maŷlis al-‘alà li-l-taqâfa, 1999).

Ibn Muqana de Alcabideche, Cascais, Alqabdaq, 1992.

«Los primeros moros conversos o el origen de la tolerancia», en L. CARDAILLAC (dir.), Toledo siglos XII-XIII. Musulmanes, cristianos y judios, Madrid, Alianza Editorial, 1992, pp. 109-117.

«La expansión del islam», Anuario de temas 1992, Madrid, Difusora Internacional, 1992, pp. 116-137.

«Toponímia árabo-valenciana. Falsos antropònims berbers», Miscel-lània Sanchis Guarner, Barcelona, Abadía de Montserrat, 1992, pp. 157-166.

"La poesía epigráfica de los palacios de la Alhambra», Realidad y símbolo de Granada, Madrid, Fundación Banco Bilbao-Vizcaya, 1992, pp. 265-271.

, «La voz de las poetisas en al-Andalus y la problemática de la voz femenina medieval», en C. SEGURA-GrAíÑo (ed.), La voz del silencio, I: Fuentes di- 
rectas para la historia de las mujeres (siglos VIII-XVIII), Madrid, Asociación Cultural Al-Mudayna, 1992, pp. 65-70.

«Una possible font árab de l'éstructura argumental de les cobles de la divisió del regne de Mallorca», Actes del novè col·loqui internacional de llengua i literatura catalanes, Barcelona, Abadía de Montserrat, 1993, pp. 161-166.

"Els arabismes del catalá. Historia d'un rebuig», Actes del novè col.loqui internacional de llengua i literatura catalanes, Barcelona, Abadía de Montserrat, 1993, pp. 301-317.

«Jarchas de posible origen galaico-portugués», Literatura medieval. Actas do IV Congresso da Associação Hispânica de Literatura Medieval (Lisboa, octubre de 1991), Lisboa, Ediçôes Cosmos, 1993, pp. 79-81.

Tirant contra el islam, Altea, Editorial Aitana, 1993.

«La dieta de Ibn Quzman. Notas sobre la alimentación andalusí a través de su literatura», en M. MARÍN y D. WAINES (eds.), La alimentación en las culturas islámicas, Madrid, Agencia Española de Cooperación Internacional, 1994, pp. 127-136.

"La ciudad como jardín y el jardín como ciudad: la Alhambra», en J.C. Rovira y J.R. NAVARro Vera (coords.), Actas del I Coloquio Internacional "Literatura y Espacio Urbano", Alicante, Fundación Cultural CAM, 1994, pp. 175-186.

«Il giardino islamico come metafora del paradiso», en Attilio PETRUCCIOLI (ed.), Il giardino Islamico. Architettura, natura, paesaggio, Milano, Mondadori, 1994, pp. 13-24.

, «Le module de la cité pétrifiée et sa présence dans la litttérature hispanique», en E. WEBER (ed.), Les Mille et une nuits. Contes sans frontière, Toulouse, Ammam, 1994, pp. 221-227.

«Introducción, en Sergio Macías», El manuscrito de los sueños, Santiago de Chile, Ediciones Zona Azul, 1994, pp. 9-12.

«El elements araboislàmics en el Tirant lo Blanc», L'Avenç, 181, 1994, pp. 50-53.

Introducción a los Estudios Árabes e Islámicos, Alicante, Universidad de Alicante, 1994. (Dir.)

, «El jardín transcendido o el jardín árabe medieval», en C. AÑón FELIU (ed.), Jardines y paisajes en el arte y en la historia, Madrid, Universidad Complutense, 1995, pp. 11-24.

«Cuando los andaluces cantaban en árabe. La poesía andalusí en época omeya», Música y poesía al sur de al-Andalus, Granada, Legado Andalusí, 1995, pp. 125-136.

«Los textos epigráficos de los palacios nazaríes. Algo más que una escritura», Arte islámico en granada. Propuesta para un museo de la Alhambra, Granada, Patronato de la Alhambra, 1995, pp. 97-115. 
«Nueva hipótesis sobre el Mancebo de Arévalo», Sharq Al-Andalus, 12, 1995, pp. 315-323.

«La familia morisca de los Muley-Fez, príncipes meriníes e infantes de Granada», Sharq Al-Andalus, 13, 1996, pp. 159-167.

«La traducción como creación literaria: Las Mil y Una Noches de Galland y Mardrus», Aproximaciones diversas al texto literario. V Coloquio celebrado en la Universidad de Murcia (20-22 de marzo de 1996), Murcia, Universidad de Murcia, 1996, pp. 525-528.

, «Las mil y una noches y el cine», en Relaciones entre el cine y la literatura: un lenguaje común. 1er Seminario, J.A. Ríos y J. SANDERSON (eds.), Alicante, Servicio de Publicaciones de la Universidad de Alicante, 1996, pp. 81-90. «Las ciudades arábigo-musulmanas de la costa oriental de la Península Ibérica (Sharq-al-Andalus) y su función comercial», en D. ABULAFIA y Blanca Garí (eds.), En las costas del Mediterráneo Occidental. Las Ciudades de la Peninsula Ibérica y del Reino de Mallorca y el comercio mediterráneo en la Edad Media, Barcelona, Ediciones Omega, 1996, pp. 95-113. (Con Míkel de Epalza.)

«La mujer en el Corán como fuente de la xaría. Posibilidad de nuevas interpretaciones», Anales de Historia Contemporánea, 13, 1997, pp. 17-23.

«Un enclave morisco en el maestrazgo turolense, Alcira de Castellote», Studium. Revista de Humanidades. Homenaje al Profesor Antonio Gargallo Moya, 4, vol. II, 1997, pp. 237-243.

- La literatura árabe clásica desde la época pre-islámica hasta la dominación otomana, Alicante, Universidad de Alicante, 1997.

, «La literatura árabe de las taifas. Poesía clásica y popular», en Los reinos de taifas, un siglo de oro en la cultura hispanomusulmana, Madrid, Real Academia de la Historia, 1997, pp. 101-103.

«Las bellas letras», en María Jesús Viguera Molíns (ed.), El retroceso territorial de al-Andalus.Almorávides y almohades. Siglos XII-XIII, "La historia de España de Menéndez Pidal", Madrid, Espasa Calpe, 1997, tomo VII, pp. 258-360.

"Tirant et l'islam», Actes del Col.loqui International "Tirant lo Blanc". Estudis crítics sobre "Tirant lo Blanc" $i$ el seu context, Barcelona, Abadía de Monserrat, 1997, pp. 429-436.

«Un relat àrab de viatge al més enllà (Buluqiya), possible font de la faula de Torroella», en Estudis de llengua i literatura en honor de Joan Veny, Barcelona, Abadía de Montserrat, 1977, pp. 71-80.

«Don Emilio García Gómez y la literatura de al-Andalus», en Elegía andaluza (Homenaje a D. Emilio García Gómez). Asociación de profesores de español, "Elio Antonio de Nebrija", Sevilla, Consejería de Educación y Ciencia de la Junta de Andalucía, 1997, pp. 81-83. 
«La lengua de mudéjares y moriscos. Estado de la cuestión», en Actas del VII Simposio Internacional de Mudejarismo (Teruel, 1996), Teruel, Instituto de Estudios Turolenses, 1999, pp. 251-278. (Con Luis F. Bernabé Pons.)

«La narrativa de origen árabe en la literatura del siglo de oro. El caso de María de Zayas», en M. Bosse, B. PotThast y A. Stoll, La creatividad femenina en el mundo barroco hispánico: María de Zayas-Isabel Rebeca Correa-sor Juana Inés de la Cruz, Kassel, Edition Reichenberger, 1999, vol. I, pp. 335-349.

"Tirant lo Blanc and the muslim world in the fifteenth century», en A. TERRY (ed.), Tirant lo blanc. New approaches, London, Tamesis, 1999, pp. 59-67.

«El erotismo de la literatura árabe y el imaginario orientalista», en M. LEDESMA PEDRAZ, Erotismo y literatura, Jaén, Universidad de Jaén, 1999, pp. 61-70.

«Estudio preliminar», en Reedición de Emilio Lafuente Alcántara. Inscripciones árabes de Granada, Granada, Universidad de Granada, 2000, pp. 9-31.

«El Rey Lobo de Murcia, Ibn Mardanis (1147-1172): promotor de la construcción de alcázares viales», en Imágenes y promotores en el arte medieval. Miscelánea homenaje a Joaquín Yarza Luaces, Barcelona, Universitat Autònoma de Barcelona, 2001, pp. 191-194.

«El islam cristianizado de los moriscos castellanos en época de Carlos V», en J. Martínez Millán (ed.), Carlos $V$ y la quiebra del humanismo político en Europa (1530-1558), Madrid, Sociedad Estatal para la Conmemoración de los Centenarios de Felipe II y Carlos V, 2001, pp. 469-485.

Carlos V, los moriscos y el Islam, Madrid, Sociedad Estatal para la Conmemoración de los Centenarios de Felipe II y Carlos V, 2001. (Ed.)

«Una falsa dicotomía: civilización occidental y civilización islámica», Vanguardia dossiers, 1, 2002, pp. 26-28.

«El judeo converso y morisco El Mancebo de Arévalo, autor de las tres culturas hispánicas», Europa e Islam tra i secoli XIV e XVI, Napoli, Accademia dei Lincei, 2002, pp. 841-856.

«Los ojos de Cherezada», Revista del Instituto Egipcio de Estudios Islámicos de Madrid, 2003, pp. 159-171.

«Los pájaros verdes de las rábitas de las dunas de Guardamar del Segura», Locus Amoenus, 7, 2004, pp. 27-33.

«Los moriscos como criptomusulmanes y la taqiyya», Actas del IX Simposio Internacional de Mudejarismo (Teruel, 2002). Actas, Teruel, Centro de Estudios Mudéjares, 2004, pp. 537-548.

«Introducción General a la lengua árabe y a su traducción al castellano», en Míkel de EpalzA (ed.), Traducir del árabe, Barcelona, Gedisa, 2004, pp. 19-42. «La traducción de la literatura árabe clásica», en Míkel DE EPALZA (ed.), Traducir del árabe, Barcelona, Gedisa, 2004, pp. 143-164.

«El erotismo en la civilización árabe clásica», en A. PÉREz JimÉnEz y M. ${ }^{a}$ Cruz SAlcedo PARrondo (eds.), Las alas del placer: Las riberas del Medite- 
rráneo bajo las flechas de Eros, Madrid-Málaga, Ediciones Clasicas \& Charta Antiqua, 2004, pp. 201-212.

__ Literatura Hispano-árabe, Alicante, Universidad de Alicante, 2004.

- Els poetes àrabs de les Illes Balears, Palma de Mallorca, Institut d'Estudis Baleàrics, 2007.

«La Alhambra: ciudad palatina y jardín del paraíso», en J.A. GONZÁLEZ AlCANTUD (ed.), La Alhambra: lugar de la memoria y el diálogo, Granada, Comares, 2008, pp. 165-182.

«El califato nazarí», Al-Qanțara, XXIX, 2, 2008, pp. 293-305. 